\title{
The suitability of the design of handbags to the tropical climate
}

\author{
Camila Osugi Cavalcanti de Alencar ${ }^{\mathrm{a}}$ and Jorge Boueri ${ }^{\mathrm{b}}$ \\ ${ }^{a}$ Graduate Program in Textiles and Fashion of School of Arts, Sciences and Humanities, University of São Paulo, \\ Rua Eça de Queiroz, 720, apt 911, Vila Mariana, São Paulo, Brazil, +55 (011) 6899-4300, \\ camilaosugi@hotmail.com. \\ ${ }^{b}$ Prof. Dr. Graduate Program in Textiles and Fashion of School of Arts, Sciences and Humanities, University of \\ São Paulo, Av. Arlindo Béttio, 1000, Ermelino Matarazzo, São Paulo, Brazil, +55 (011) 3091-1034, \\ jjboueri@usp.br.
}

\begin{abstract}
This work encourages the exercise of consideration, observation and critical reading of the design of handbags and the relation to the conditions imposed by tropical climate. Our purpose is to highlight some critical and conceptual thoughts on the matter of the design of fashion accessories in Brazil, ergonomics and aesthetic- functional relation. Through physical concepts is possible to propose consistents solutions compatible with the reality of the costumers living on Brazilian coast.
\end{abstract}

Keywords: ergonomics, handbags design, the Brazilian coast.

\section{Introduction}

From the fashion standpoint, it is important to critically analyze the design of handbags offered by the Brazilian market in order to identify, through the ergonomic study, parameters to be applied in the methodology of the project that promote the suitability of handbags to the needs of users from tropical climate coastal regions. The intent is to reflect on the relationship between the product and its functionality, concerning thermal comfort, in order to polish the design of handbags.

Nowadays, in fashion design it is common to see the user's needs limited to socio-psychological comfort. However, as an extension of the body in performing everyday tasks, the handbags cannot be away from functionality concerns.

The study of the form as means of suitability of the accessory to the climate aims to provide improved usability. The adequacy of the design to the mesological conditions of the tropical coastal reaches its goal when the design is thought of as the scientific interpretation of the local conditions, establishing harmony between the user, the design, the product and the demands of the environment.

\section{Theoretical Development}

The main reason is to promote parameters for the design of handbags more consistent with the reality of people living in the coastal region. Through the study of ergonomics and concepts embodied by the Architecture as an aspect of the project methodology, the production of a design suitable to the environment was carried out.

By improving the aesthetic and functionality relation of the accessory, the interaction with the user is enhanced. Thus, by optimizing the use of the product, it is possible to eliminate waste and reduce pressure over natural resource, pursuing conscious consumption.

\section{Case Study}

The fact that Brazil is a known by being a tropical country having $92 \%$ of its territory placed between the line of the Equator and the Tropic of Capricorn causes the climate to directly interfere in the lifestyle of its people. Despite being a privilege, the incidence of direct sunlight can damage the handbags, deforming and wearing them out, compromising its purpose. For example, leather and synthetic materials used in the manufacturing of 
handbags, under large sun exposure may crackle and peel, reducing the products life cycle and user's comfort, preventing proper transport of sensitive objects, such as food and make up from occurring satisfactorily.

In tropical climates, solar radiation may be considered one of the variables of greatest impact, due to thermal discomfort caused by the absorption of solar energy that reaches the surface and affect the relation user/object. Thus, the design of the fashion accessory targeted for the use in the tropical coastline should consider the eco-friendly relationship between ergonomics and textile comfort.
To that end, textile comfort becomes primordial on the products used in this environment and ergonomics becomes the initial part of the design of fashion accessories as essential scientific information to the sustainability of the system.

Thermal comfort, one of those responsible for environmental quality, can be achieved through the adoption of passive environmental control systems (Physical law of reflection and refraction of light - Fig 1), for it controls thermal gains and improves the distribution of light. According to the external form, the material loses the function of being a simple gasket and gains structural role as responsible by thermal inertia.
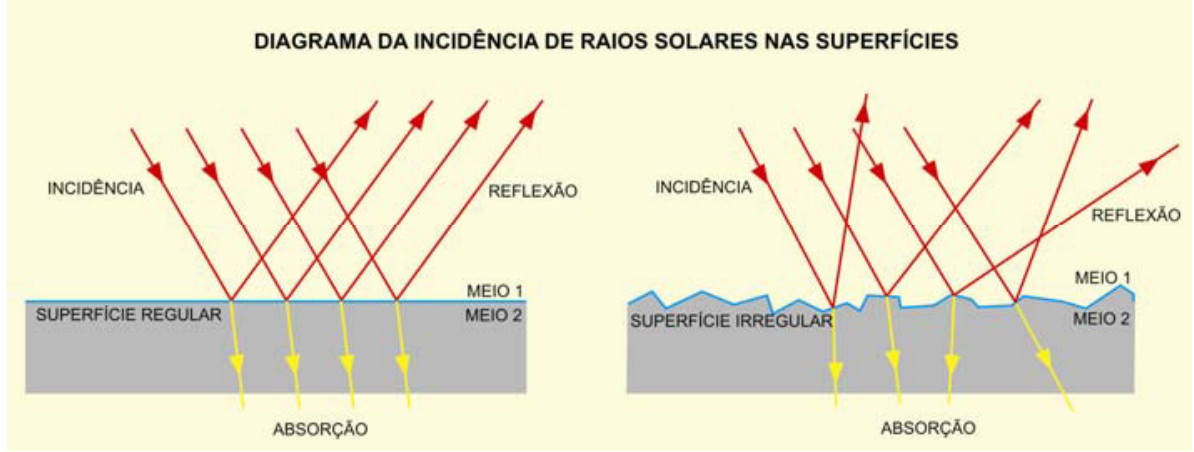

Fig 1. Schematic of the Law of Physics Reflection and Refraction of light at regular and irregular surfaces. (Source: Own Collection, 2011)
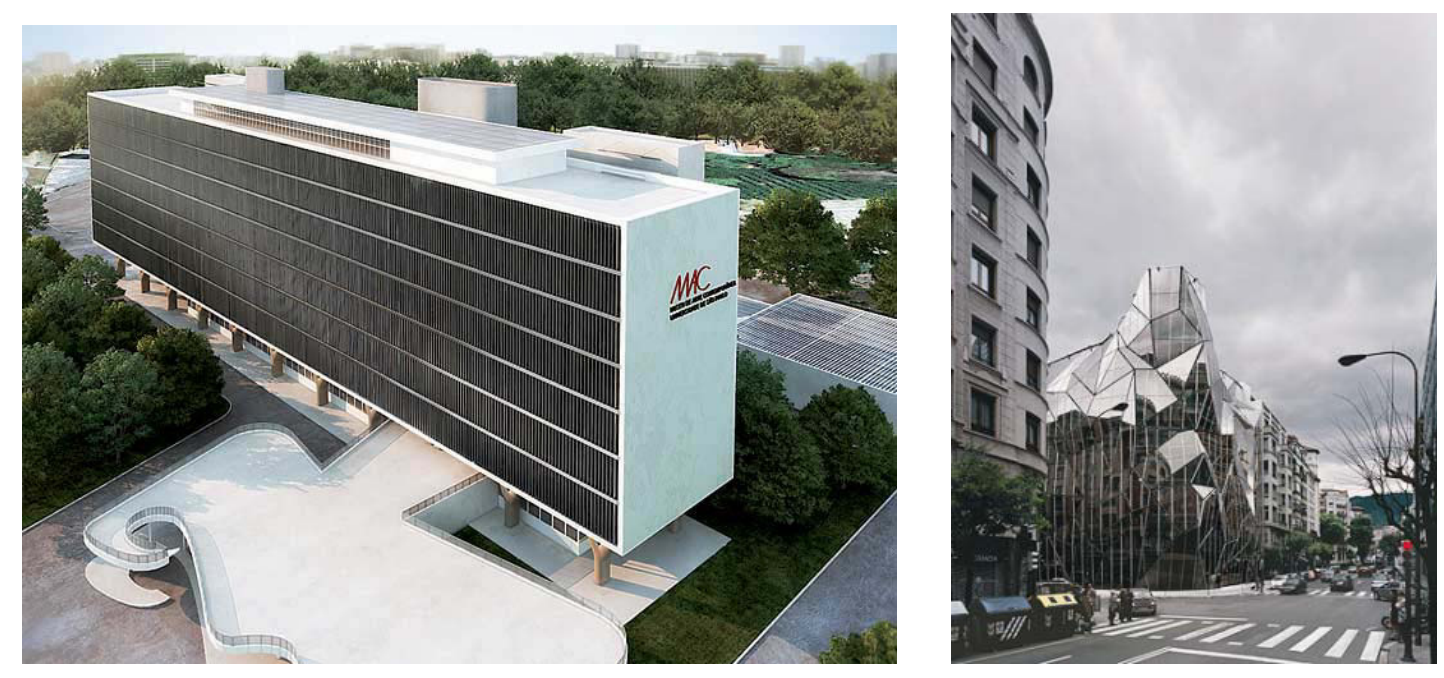

Fig 2. Comparative examples of projects in architecture. Facade rectangular with smooth surface and segmented with irregular surfaces. (Source: www.google.com.br/images, 2011) 


\section{Conclusion}

The architecture of fashion accessories (Fig 2), represented through the design of handbags should provide comfort and satisfaction to the user. Hence the importance of design in obtaining textile comfort through the study of ergonomics and promotion of the functionality of handbags (Fig 3) used in the Brazilian coast, establishing the proper thermal environment to human activities and duties and, therefore, the user's comfort through satisfaction, of human performance and energy conservation promoted by thermal neutrality.

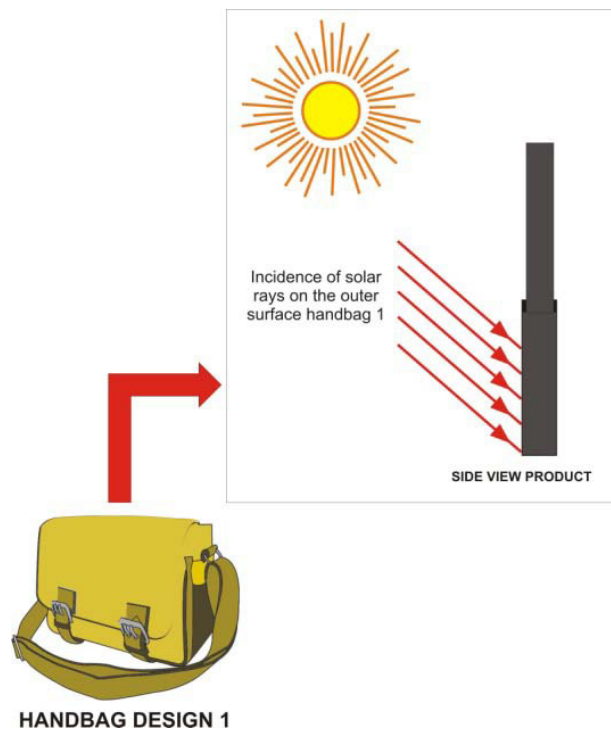

To minimize the negative effects of sunlight incidence on the handbag, physical laws of Reflection and Refraction are used.

The segmentation on surfaces forming a mosaic with several guidelines enables the absorption of sunlight to be mitigated and, at the same time, makes the volumetry of the object interesting, creating several plans (Fig 4).

In this sense, the design of handbags appears as one of the responsible for offering compatible thermal conditions to the textile comfort, good functionality, aiming to minimize interference from sunlight on the bag and polish its aesthetic and functional relation.

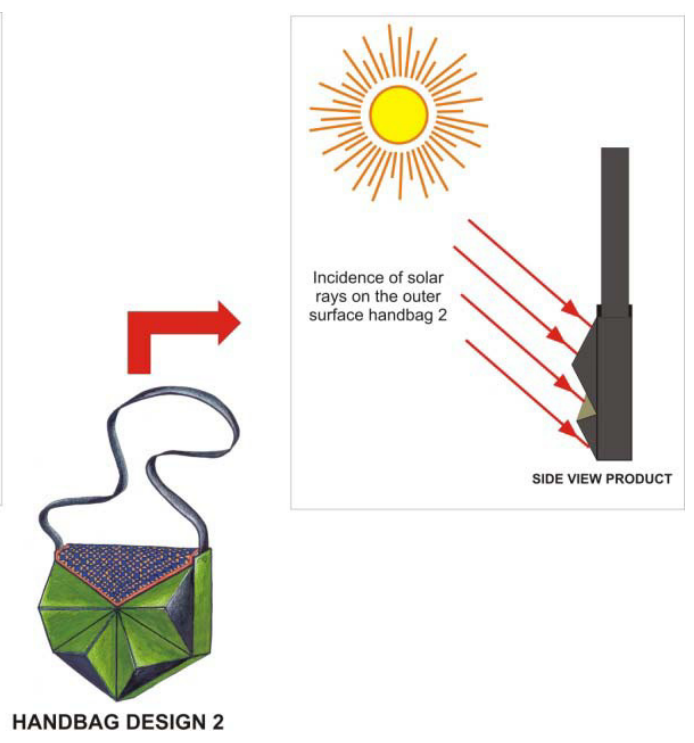

Fig 3. Analyze the design of handbags: relationship of incidence of solar rays in the shape of the handbags. (Source: Own Collection, 2011)

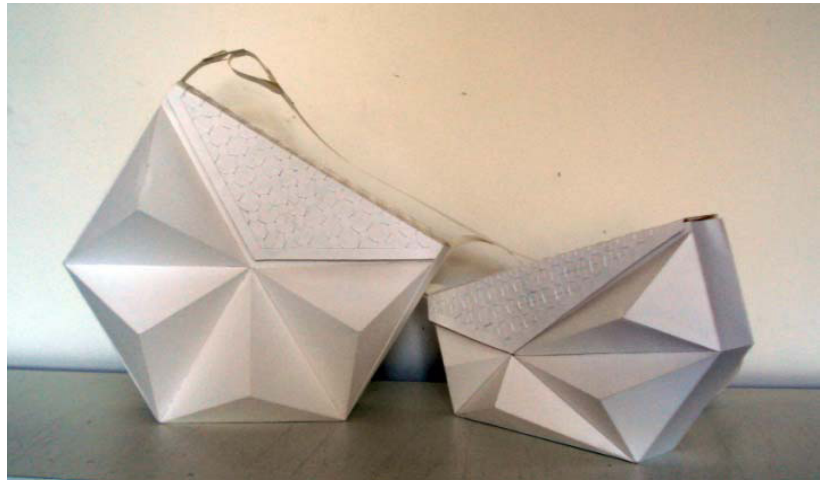

Fig 4. Prototype of handbags in order to minimize the effects of UV rays.(Source: Own Collection, 2011)

\section{References}

(1) K. Castilho and C. Garcia, Moda Brasil: Fragmentos de um Vestir Tropical, Anhembi Morumbi. (2001), São Paulo, SP.

(2) B. Lobach, Design Industrial. Bases para a configuração dos produtos industriais, Edgar Blucher. (2001), São Paulo, SP.

(3) M. Baxter, Projeto de Produto: Guia Prático para o Design de Novos Produtos, Edgar Blucher. (2000), São Paulo, SP.

(4) I. Iida, Ergonomia: projeto e produção, Edgard Blucher
(2005), São Paulo, SP.

(5) E. Manzini and C. Vezzoli, O Desenvolvimento de Produtos Sustentáveis, Edusp. (2008), São Paulo, SP.

(6) A. Moraies, Ergonomia e usabilidade de produtos, programas, informação, 2AB. (2001), Rio de Janeiro, RJ.

(7) ASHRAE INC. Thermal Environmental conditions for Human Occupancy (THCHO Stantard 55-2004.(2004).Atlanta, GA. 